\title{
An Enzyme Free Potentiometric Detection of Reducing Sugars Based on a Poly(3-hydroxyphenylboronic acid-co-phenol) Molecularly Imprinted Polymer Modified Electrode
}

\author{
Yalin Wu, Qian Wang, Miaomiao Chen, Chao Dong, Xiuhua Zhang*, Shengfu Wang
}

Department of Hubei Collaborative Innovation Center for Advanced Organic Chemical Materials, Ministry-ofEducation Key Laboratory for the Synthesis and Application of Organic Functional Molecules, College of Chemistry and Chemical Engineering, Hubei University, Wuhan, 430062, China

*Corresponding Author

Xiuhua Zhang

Department of Hubei Collaborative Innovation Center for Advanced Organic Chemical Materials

Ministry-of-Education Key Laboratory for the Synthesis and Application of Organic Functional Molecules

College of Chemistry and Chemical Engineering

Hubei University

Wuhan, China

Tel: +86-027-50865309

Fax: +86-027-88663043

E-mail: zhangxh@hubu.edu.cn

\begin{tabular}{l|l|l} 
Received: 09 October 2015; & Revised: 29 February 2016; & Accepted: 16 March 2016
\end{tabular}

\begin{abstract}
An enzyme free potentiometric sensor for reducing sugars (glucose and fructose) based on molecularly imprinted polymer (MIP) modified on glassy carbon electrode was systematically investigated. It was expected to work like a solid ion selective electrode (ISE) where the specific carrier are the imprinted sites. The polymer for the selective recognition of glucose and fructose were synthesized by coelectropolymerizing the 3-hydroxyphenyl boronic acid and phenol with reducing sugar (glucose or fructose) complex. The phenol could not only provide more hydroxyl but also promote the electron transfer because of its benzene ring structure and oxygen. The principle of reducing sugars detection at the MIP modified glassy carbon electrode (MIP/GCE) was to form a covalent binding which was reversible when changing the binding conditions and had a quick response to the electrochemical potential of the fabricated sensor. The imprinted polymer films covered on the electrode surface could improve the sensitivity of the sensor response remarkably. Under the optimal experimental conditions, the potential change and the concentration of glucose and fructose were linearly related from 0.75 to $18 \mathrm{mM}$. The detection limit of glucose and fructose was $0.23 \mathrm{mM}$ and $0.35 \mathrm{mM}$, respectively. In addition, we had successfully evaluated the applicability of the sensitive sensor according to detect reducing sugars in practical samples.
\end{abstract}


Keywords: Potentiometric sensor; Reducing sugars; Poly(3-hydroxyphenylboronic acid-co-phenol); Molecularly imprinted polymers.

\section{Introduction}

In the field of chemical analysis applications, glucose and fructose were investigated extensively during the last several years [1-4], which were associated with the entire industrial process from the payment of the producer to the production of sugar. Therefore, a sensitive and reliable method is urgently needed for the selective determination of glucose and fructose to control the production of derivatives. A number of studies based on various detection methods such as high performance liquid chromatography (HPLC)/evaporative light scattering detection (ELSD) [5], fluorimetry [6], colorimetry [7], spectrophotometry [8], gas chromatography (GC)/mass spectrometry (MS) [9] and chromatographic [10] have been cited in the literature. Compared with the above analytical methods, electrochemical method [11] is simple and low cost. Biosensor has gained much attention these years [12-13]. Since the first enzymatic glucose sensors were introduced by Clark and Lyons in 1962 [14], the field of enzyme-based glucose sensors has progressed rapidly with increasingly innovative and efficient. Due to the high specificity of enzyme to its cognate substrate, glucose oxidase is a good candidate for the fabrication of glucose sensors. However, these types of sensors can be easily affected by environmental factors, including temperature, $\mathrm{pH}$, humidity and the presence of toxic chemicals, bringing about a higher requirement on material selection and operation conditions [15-17]. As a result, recent studies have focused on producing non-enzymatic sensors that are practical, simple, robust, and obtainable at a low-cost [18-20].

Recently, much attention have been paid to the development of glucose or fructose sensors based on boronic acid [21-22] and its derivatives as recognition components because boronic acid can form covalent bonds with reducing sugars to generate cyclic boronate esters in nonaqueous or basic aqueous media [23-25]. The complexity of reducing sugars and phenol produce a stable ester with aromatic boronic acids, where the binding constant depends on $\mathrm{pH}$, electrolyte concentration and the $\mathrm{p} K_{\mathrm{a}}$ of aromatic boronic acid [26]. A molecular recognition, phenylboronic acid, exhibit an ideal synthetic molecular receptor which has the ability to recognise saccharides selectively. Phenylboronic acid derivatives have been developed for reducing sugars sensor in electrochemical detection [27-29], which was a promising read-out method for its relative technical simplicity and the ease of miniaturization.

Shoji developed a novel electrochemical approach using poly(aniline boronic acid) modified electrode for the potentiometric detection of saccharides. A model was described in which the electrochemical potential was sensitive to the change in the $\mathrm{p} K_{\mathrm{a}}$ of the conducting polymer as a result of boronic aciddiol complexation [28]. A potentiometric glucose sensor was developed through the electrochemical preparation of poly (aniline boronic acid) nanotubes on gold electrode [29].

The molecularly imprinted technique has been known as an accurate, selective and sensitive pretreatment method for detecting trace amounts of chemicals [30]. Molecularly imprinted polymers (MIPs), which are particular for a given target molecule, have been considered as promising candidates for replacing the biological recognition elements since they have superior mechanical stability, chemical selectivity, low cost and are simple to prepare [31]. During the processing of synthesizing polymer, functional monomers react with crosslinking monomer and then co-polymerized through covalent bonds or non-covalent bonds with the target analyte as the imprinted molecule [32-33]. Because of the specific recognition systems formed by the interactions between template and monomers, MIPs could recognize the template molecular from a mixture of 
compounds with similar structure [34]. During recent years, the MIPs have been well used for the detection of small biological molecules such as environmental antibiotics [35], pollutants [36], pesticides [37], and biomacromolecule such as bovine hemoglobin [38], chromato graphic separation [39], solid-phase extraction [40] and chiral separation [41]. In addition, the MIPs have also gained wide acceptance as new molecular recognition materials in chemical sensors [4248]. Thus, the MIPs would be a promising alternative ionophore for potentiometric analysis in complex.

In our study, we present a novel electrochemical method with imprinted polymers which is fabricated on glassy carbon electrode by means of 3-hydroxyphenyl boronic acid and phenol as the monomer, and glucose or fructose as the template molecule to realize the selective detection of reducing sugars. Boronic acid can combine with glucose or fructose in the imprinted polymer matrix according to covalently linkage, under the circumstances, it is a potential method to improve the selective detection of sugar. As far as we know, there are few reports on the MIPbased potentiometric sensor which is applied to detect glucose and fructose. Compared with a modified nanotubes on gold electrode [29], even though our works have a similar liner range and detection limit, the as-prepared glassy carbon electrode exhibits the features of stability and simple fabrication. Since sensors for sugar have been widely developed and applied, the electrochemical glucose sensor has been commercialized for years actually. Compared with the as-prepared glucose sensor, commercial glucose sensors are quite sensitive and responsive in strict matrix environment that is because most of them are enzyme-based sensors. While the asprepared glucose sensor has a broader detection range and a longer working life, and it can function properly in alkaline environment. In the current work, we developed a method based on decorating glucose-MIP and fructose-MIP films onto a glassy carbon electrode, respectively, which is simple, rapid and selective.

\section{Experimental}

\subsection{Chemicals and materials}

3-hydroxyphenylboronic acid (98\%) and Phenol were supplied by Aladdin Reagent Ltd. (Shanghai, China). Glucose, fructose, xylose, sucrose and galactose were purchased from Sigma-Aldrich. The supporting electrolyte used for the electrochemical studies was $0.1 \mathrm{M}$ phosphate buffer solution (PBS), prepared by $\mathrm{Na}_{2} \mathrm{HPO}_{4}$ and $\mathrm{KH}_{2} \mathrm{PO}_{4}$ and the $\mathrm{pH}$ was adjusted by $\mathrm{H}_{3} \mathrm{PO}_{4}$ or $\mathrm{NaOH}$. All other reagents and chemicals were of analytical reagent grade and doubly distilled water was used though the whole process of the experiments.

\subsection{Instrumentation and measurements}

A CHI660C electrochemical workstation (Shanghai CHI Instruments, China) was used for electrochemical analysis. Cyclic voltammogram (CV) and electrochemical impedence spectroscopy (EIS) were conducted in a conventional three-electrode system with a platinum wire as auxiliary electrode, saturated calomel electrode (SCE) as reference electrode and the modified or bare glassy carbon electrode (3.0 $\mathrm{mm}$ diameter, GCE) as the working electrode. Potentiometric measurements were performed by open circuit method. Unless otherwise stated, all open circuit experiments were conducted in a stirred PBS at $\mathrm{pH}$ 10.0. The electrode potential was allowed to settle in the buffer solution prior to performing all open circuit measurements. After the modified electrode settled, the value of open circuit potential $\left(E_{\mathrm{oc}}\right)$ was recorded over the change of time before and after the adding of glucose or fructose. $\Delta E$ was the $E_{\mathrm{oc}}$ value of $0.1 \mathrm{M}$ PBS with glucose after the background signal of $0.1 \mathrm{M}$ PBS without glucose was subtracted. All the electrochemical experiments were conducted at room temperature (about $25^{\circ} \mathrm{C}$ ).

\subsection{Chemical modification of the electrodes}

Prior to modification, a bare GCE was carefully polished with $0.05 \mu \mathrm{m}$ alumina powder $\left(\gamma-\mathrm{Al}_{2} \mathrm{O}_{3}\right)$ on chamois leather to obtain a mirror like surface and cleaned ultrasonically in water 
and ethanol, respectively. Equimolar 3hydroxyphenylboronic acid and D-glucose in 0.1 M PBS ( $\mathrm{pH}=10.0)$ reacted for $2 \mathrm{~h}$ to get the glucose-3-hydroxyphenylboronic acid complex. The glucose-molecularly imprinted polymer (Glu-MIP) films were deposited on bare GCE by electropolymerizing $100 \mathrm{mM}$ phenol and $25 \mathrm{mM}$ of the specific glucose-3-hydroxyphenylboronic acid complex in $0.1 \mathrm{M}$ PBS ( $\mathrm{pH}$ 10.0). Electropolymerization was carried out using two successive cyclic voltammetry scans, and the potential was scanned between 0.0 and $+0.6 \mathrm{~V}$ vs $\mathrm{SCE}$ at a scan rate of $10 \mathrm{mV} \cdot \mathrm{s}^{-1}$ in the unstirred solution. For comparison, non-imprinted polymer
(NIP) films were fabricated following the same procedure, but without glucose. After electropolymerization, the modified electrodes were washed with $0.1 \mathrm{M} \mathrm{HCl}$ for $20 \mathrm{~min}$ to remove the imprinting molecules. In these conditions, imprinting molecules could escape to form the stereo cavity of the molecularly imprinting membranes due to the destruction of the covalent interactions between reducing sugars (glucose and fructose) and the molecular imprinting membranes (Scheme 1). Under the same conditions, the fructose-molecularly imprinted polymer (Fru-MIP) films were prepared by the same method.
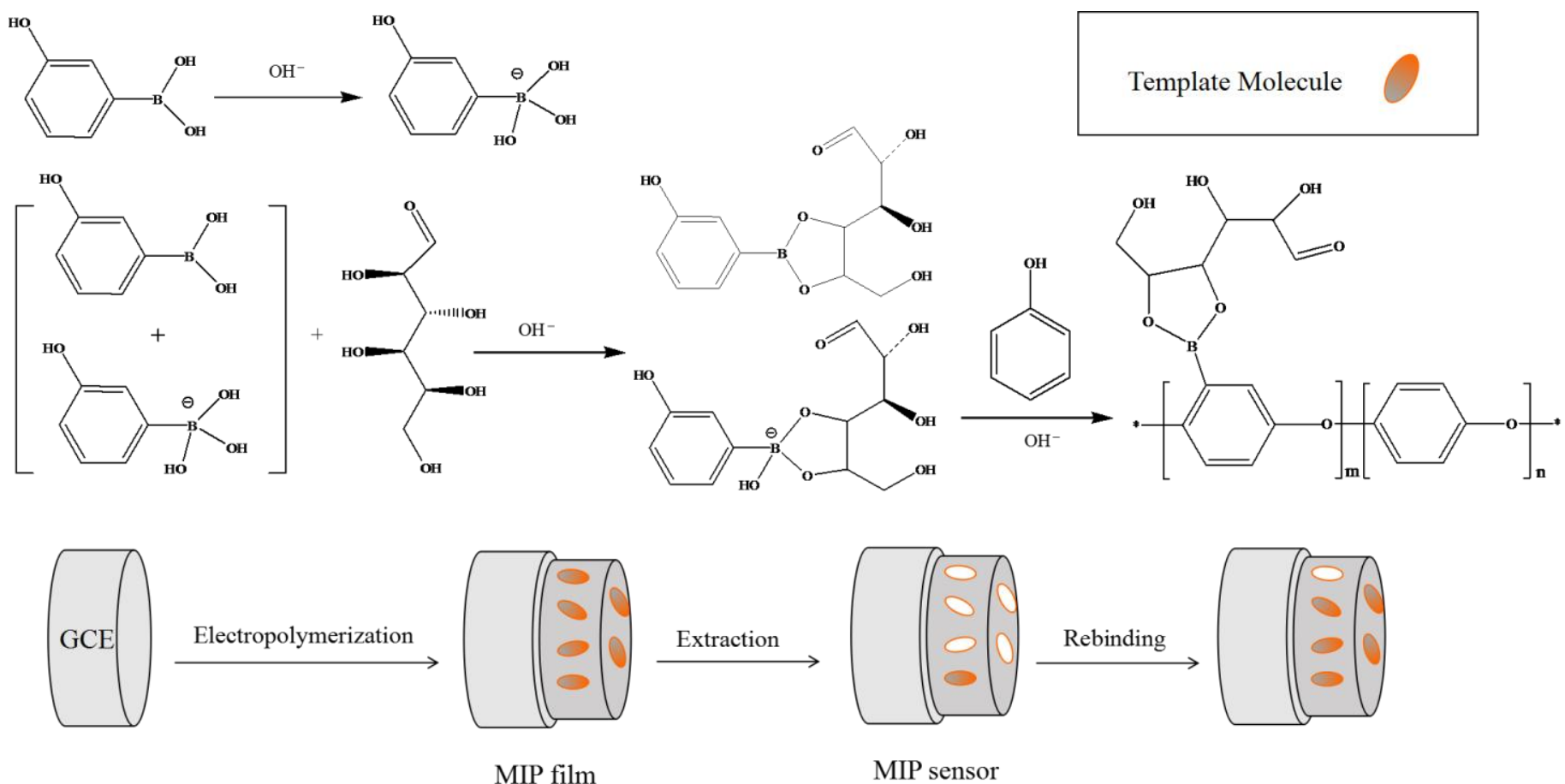

Template Molecule

Scheme 1. Schematic formation of cyclic phenylboronate ester via boronic acid site binding with glucose and the preparation of MIP sensor.

\section{Results and Discussion}

\subsection{Fabrication and characterization of the MIP/GCE}

The imprinted films were electropolymerized on the surface of bare GCE by cyclic voltammograms scanning in a $0.1 \mathrm{M}$ PBS $(\mathrm{pH}$ 10.0). As shown in Fig. 1, in the first scan, an irreversible anodic oxidation peak appeared at potential of $+0.45 \mathrm{~V}$. Afterwards, the anodic current disappeared with the second cycle, indicating the formation of non-conductive film on the electrode surface [44]. No significant difference was observed between the cyclic voltammograms obtained in the presence of glucose and in the absence of that (results not shown) during the polymerization. The behavior of electropolymerization reaction with fructose 
was similar to that of the glucose (results not sugars did not have electroactivity on the GCE. shown). These results demonstrated that reducing

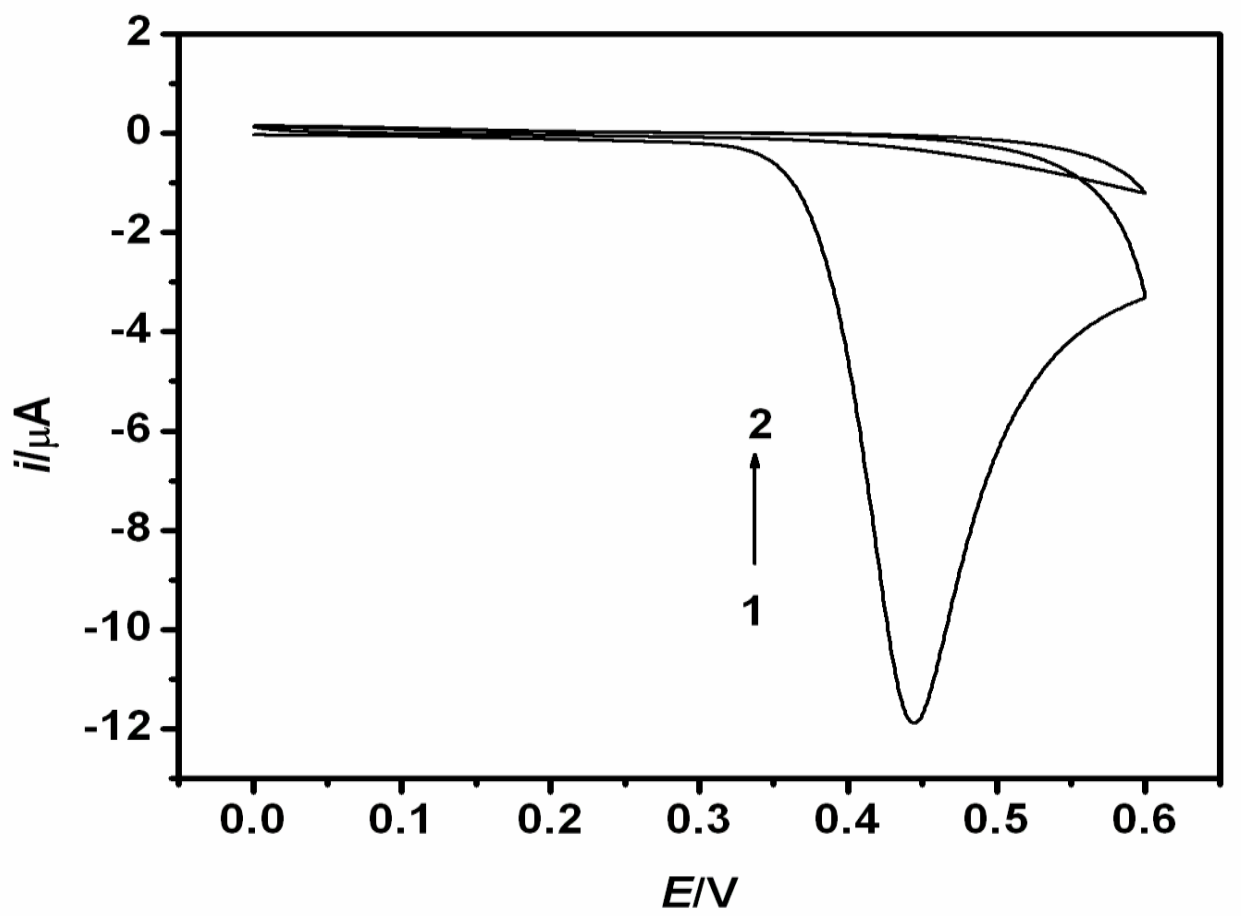

Figure. 1. Cyclic voltammograms for the electropolymerization of $100 \mathrm{mM}$ phenol and $25 \mathrm{mM}$ of the specific glucose3-hydrooxyphenylboronic acid complex in $0.1 \mathrm{M} \mathrm{PBS}$ ( $\mathrm{pH} 10.0)$. The scan rate is $10 \mathrm{mV} \cdot \mathrm{s}^{-1}$.

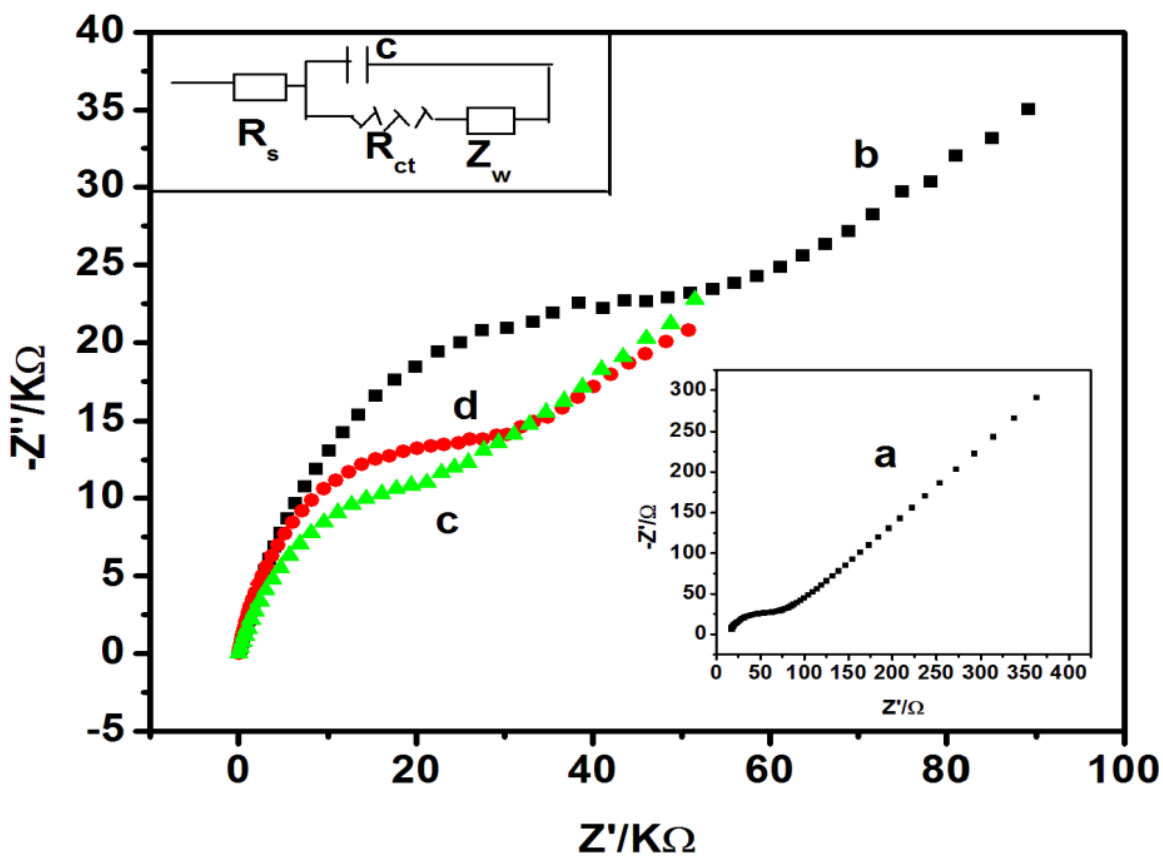

Figure. 2. (A) Electrochemical impedance spectra in $5.0 \mathrm{mM} \mathrm{K} 3 \mathrm{Fe}(\mathrm{CN}) 6$ on the bare GCE (a); after electropolymerization (b); Glu-MIP/GCE after removal of glucose (c); Glu-MIP/GCE after rebinding (d). Potential: $0.220 \mathrm{~V}$, frequency range: $100 \mathrm{mHz}$ to $100 \mathrm{kHz}$, alternating potential: $5 \mathrm{mV}$. 
EIS is an efficient tool for studying the interface properties of surface-modified electrodes. Generally, a typical shape of EIS includes a semicircle region and a straight line. The semicircle part, which can be observed at higher frequency, corresponds to the electrontransfer-limited process, whereas the linear part is the characteristic of the lower frequency range and represents the diffusion-limited electrontransfer process. The semicircle diameter equals the electron-transfer resistance, $R_{\mathrm{ct}}$, which is related to the charge-transfer kinetics of the redox probe at the electrode surface. Fig. 2 shows the changes in the EIS of the various electrodes in $5.0 \mathrm{mM} \mathrm{K} \mathrm{K}_{3} \mathrm{Fe}(\mathrm{CN})_{6}$. The increased resistance from curve a to curve $\mathrm{b}$ could be attributed to the produced film that covered the surface of bare GCE. The decrease of resistance from curve $b$ to curve $\mathrm{c}$ could be attributed to the cavities which were beneficial for the charge transfer of the redox probe between the electrolyte solution and the electrode. The increased resistance from curve $\mathrm{c}$ to curve $\mathrm{d}$ signified that glucose was rebounded to the film. This verified that the MIP film has good capability to distinguish the target molecule.

\subsection{Potentiometric response of Glu-MIP/GCE to glucose}

As shown in Scheme 1, boronic acid are known to bind diol compounds including sugars to form cyclic boronate esters that are negatively charged as a result of the addition of cis-diol groups from solution. The effect of complexation on the electrochemical potential was cause the change of potential $(\Delta E)$. Fig. 3 shows a comparison of potentiometric response of glucose as a function of time at different electrodes. As shown in Fig. 3, a stepwise increase in $\Delta E$ was observed upon addition of glucose at the GluMIP/GCE. As for the measurement of glucose at Glu-NIP/GCE under identical conditions, although a potentiometric increase could be obtained. The potentiometric signal at the GluNIP/GCE revealed a distinct decrease compared with the Glu-MIP/GCE. An experiment at the bare GCE displayed unobvious increase for the potentiometric signal. The results demonstrated that the Glu-MIP/GCE sensor enhanced the sensitivity for glucose detection.

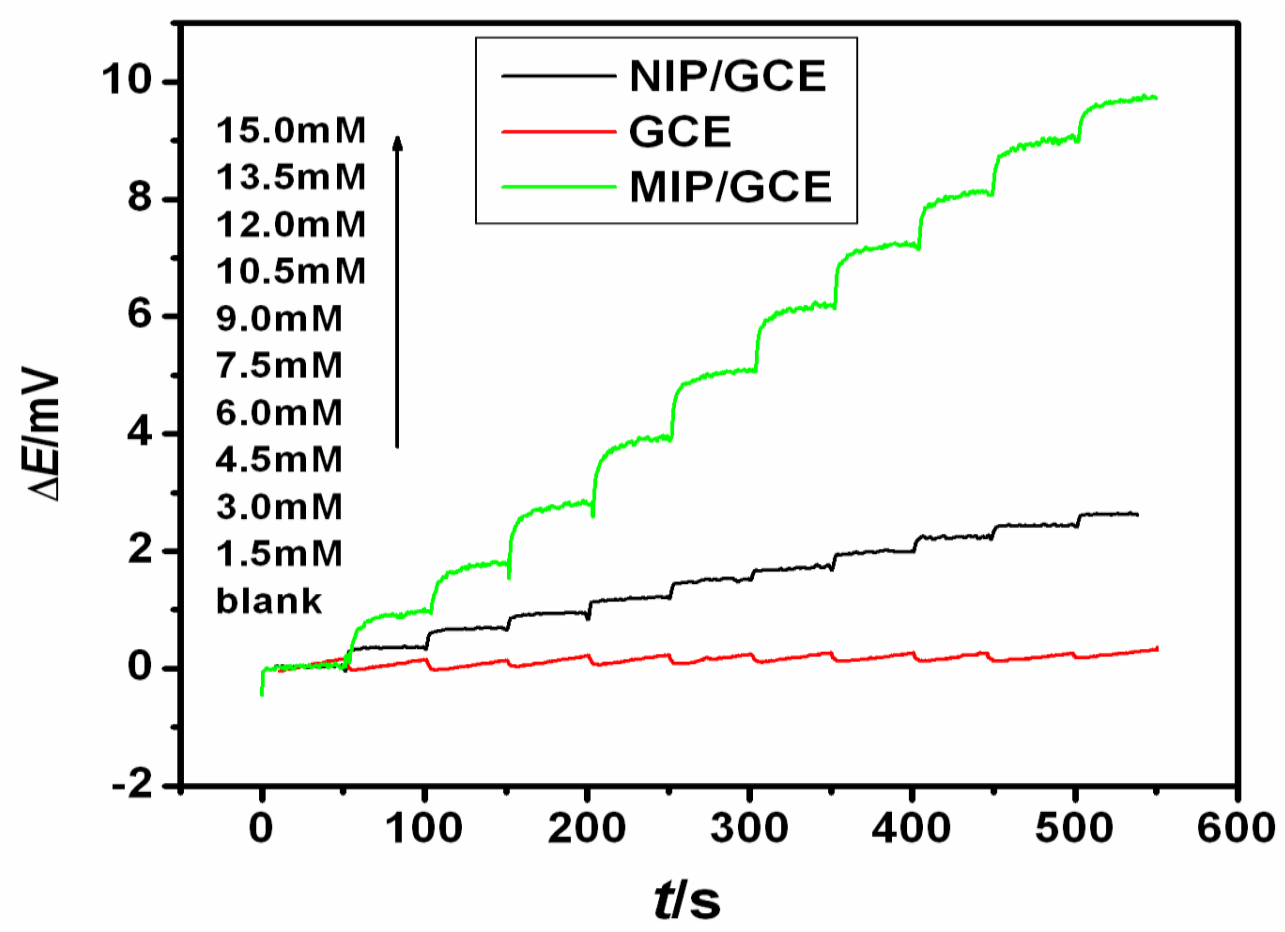

Figure. 3. Potentiometric response $(\Delta E)$ of glucose in $0.1 \mathrm{M} \mathrm{PBS}(\mathrm{pH} 10.0)$ as a function of time at different electrodes. 


\subsection{Optimization of potentiometric analysis parameter}

\subsubsection{Effect of monomer ratio}

The mole ratio of 3-hydroxyphenylboronic acid and phenol monomer during the polymerization process was essential for the formation of defined recognition sites in MIP polymer matrix. The stable shape of complementary cavity for the imprinted process could not be maintained with a little phenol monomer. An increase of phenol amount could enhance the stability of the structure of the selective cavities. However, excessive phenol may result in the decrease of the cavities. To choose a suitable amount of phenol and optimize the polymerization process, the effect of the molar ratio of 3-hydroxyphenylboronic acid and phenol monomer on the performance of GluMIP/GCE was investigated in the range of 1:0, $1: 2,1: 4,1: 6$, and the obtained results are shown in Fig. 4A. The variation of molar ratio of 3hydroxyphenylboronic acid and phenol monomer exhibited a significant difference in the sensor response, and the molar ratio of 1:4 gave the best response in terms of the addition of glucose.

\subsubsection{Effect of $\mathbf{p H}$ value of PBS}

The $\mathrm{pH}$ effect was investigated by following the variation of potential in different value of $\mathrm{pH}$ by addition of glucose. The $\mathrm{pH}$ of the solution was varied within the $\mathrm{pH}$ range of 6.0-12.0 in order to optimize the $\mathrm{pH}$ in determining glucose at Glu-MIP/GCE. As seen in Fig. 4B the response signal increased in the $\mathrm{pH}$ range of 6.0 to 10.0 and then decreased. As illustrated in Scheme 1, Boronic functional groups participate in complexation with compounds containing vicinal diols through reversible ester formation, the complexification produces a stable boronate anion, and a proton, therefore the Eoc is sensitive to the $\mathrm{pH}$ value within the film, and a steady-state response is consistent with a change in $\mathrm{pKa}$ of polymer film, and following protonation [44]. The increased response reached maximum at $\mathrm{pH}$ 10.0 and it was commonly believed that the binding constants reach a maximum while the $\mathrm{pH}$ was higher than that the $\mathrm{pKa}$ of the boronic acid species. As illustrated in Fig. 4B maximum glucose response of Glu-MIP/GCE was obtained at $\mathrm{pH} 10.0$, which was the value used throughout the study.
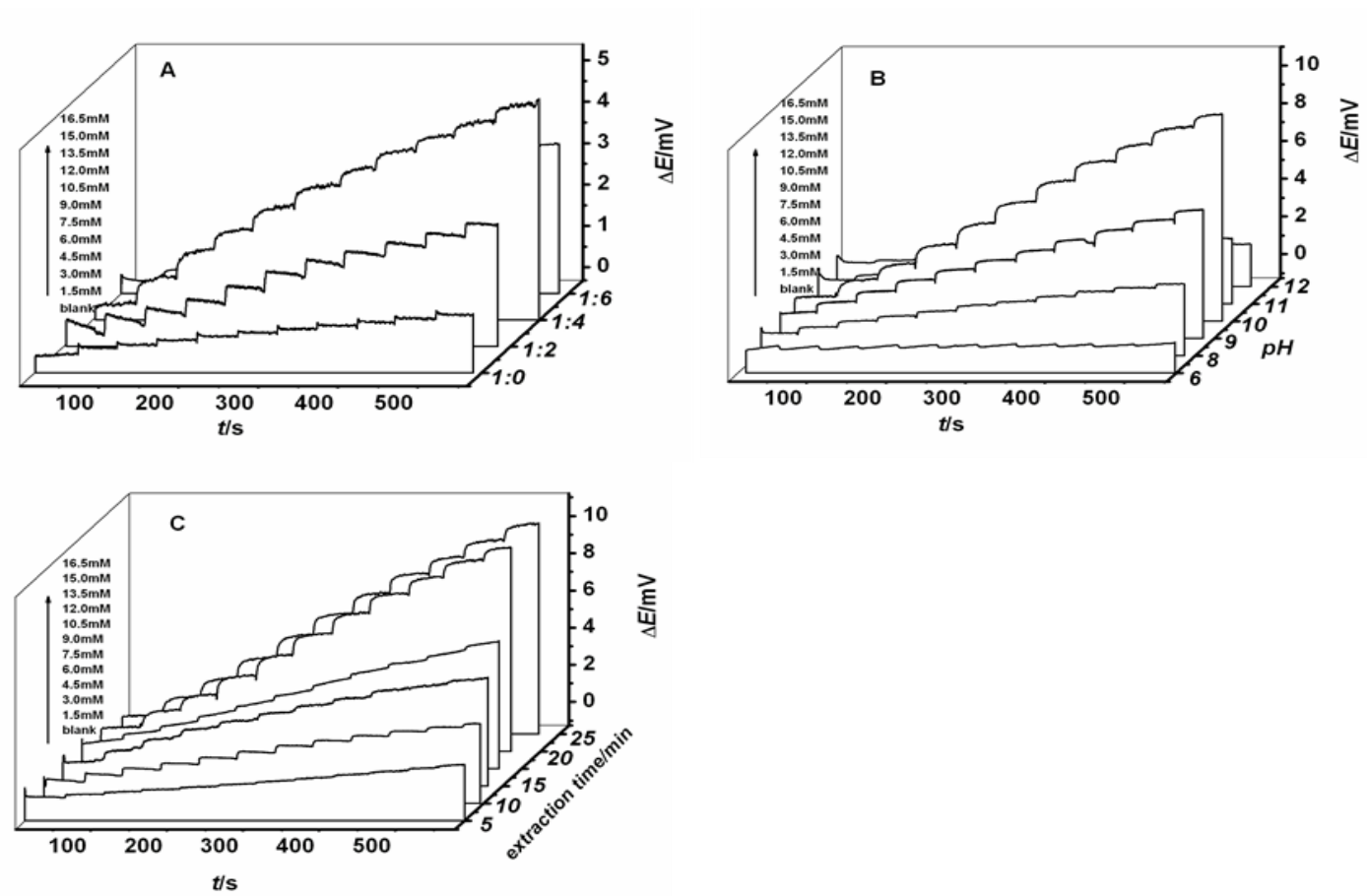

离

Figure. 4. Potentiometric responses $(\Delta E)$ for the glucose detection at the Glu-MIP/GCE: (A) Effect of monomer ratio; (B) Effect of $\mathrm{pH}$ value of $0.1 \mathrm{M}$ PBS; (C) Effect of different extraction time in $0.1 \mathrm{M} \mathrm{HCl}$. 


\subsubsection{Effect of different extraction time}

The solution of $0.1 \mathrm{M} \mathrm{HCl}$ was used to study the influences of different extraction time of GluMIP/GCE. As shown in Fig. 4C, the potentiometric response of glucose increased along with the increase of extraction time and then reached equilibrium at $20 \mathrm{~min}$. It turned out that the optimal time of extraction was $20 \mathrm{~min}$ which was used throughout the study.

\subsection{Potentiometric measurements at Glu- MIP/GCE}

Under the experimentally derived optimum conditions above, the sensitivity of the GluMIP/GCE and Fru-MIP/GCE were evaluated by a typical potentiometric response after addition of successive aliquots of glucose and fructose to 0.1 M PBS (pH 10.0), respectively. As shown in Fig.
$5 \mathrm{~A}$ and $5 \mathrm{~B}$, the calibration curve equation for glucose was $\Delta E(\mathrm{mV})=0.686 c(\mathrm{mM})+0.091$ with $R^{2}=0.998$ and that for fructose was $\Delta E(\mathrm{mV})$ $=0.446 c(\mathrm{mM})+0.138$ with $R^{2}=0.998$. The signal was obtained the average of multiple repeats ( $n$ $=3$ ). The linear response was from $0.75 \mathrm{mM}$ to 18 $\mathrm{mM}$. Therefore, the sensitivity was calculated to be $0.686 \mathrm{mV} \cdot \mathrm{mM}^{-1}$ for glucose and 0.446 $\mathrm{mV} \cdot \mathrm{mM}^{-1}$ for fructose according to the slope of calibration curves. The detection limit was estimated to be $0.23 \mathrm{mM}$ for glucose and 0.35 $\mathrm{mM}$ for fructose at a signal-to-noise ratio of 3 . This new sensing platform is of significant sensitivity, which is better than some of previously reported saccharide sensors[24,27,29,45-52]. The results are listed in Table 1.
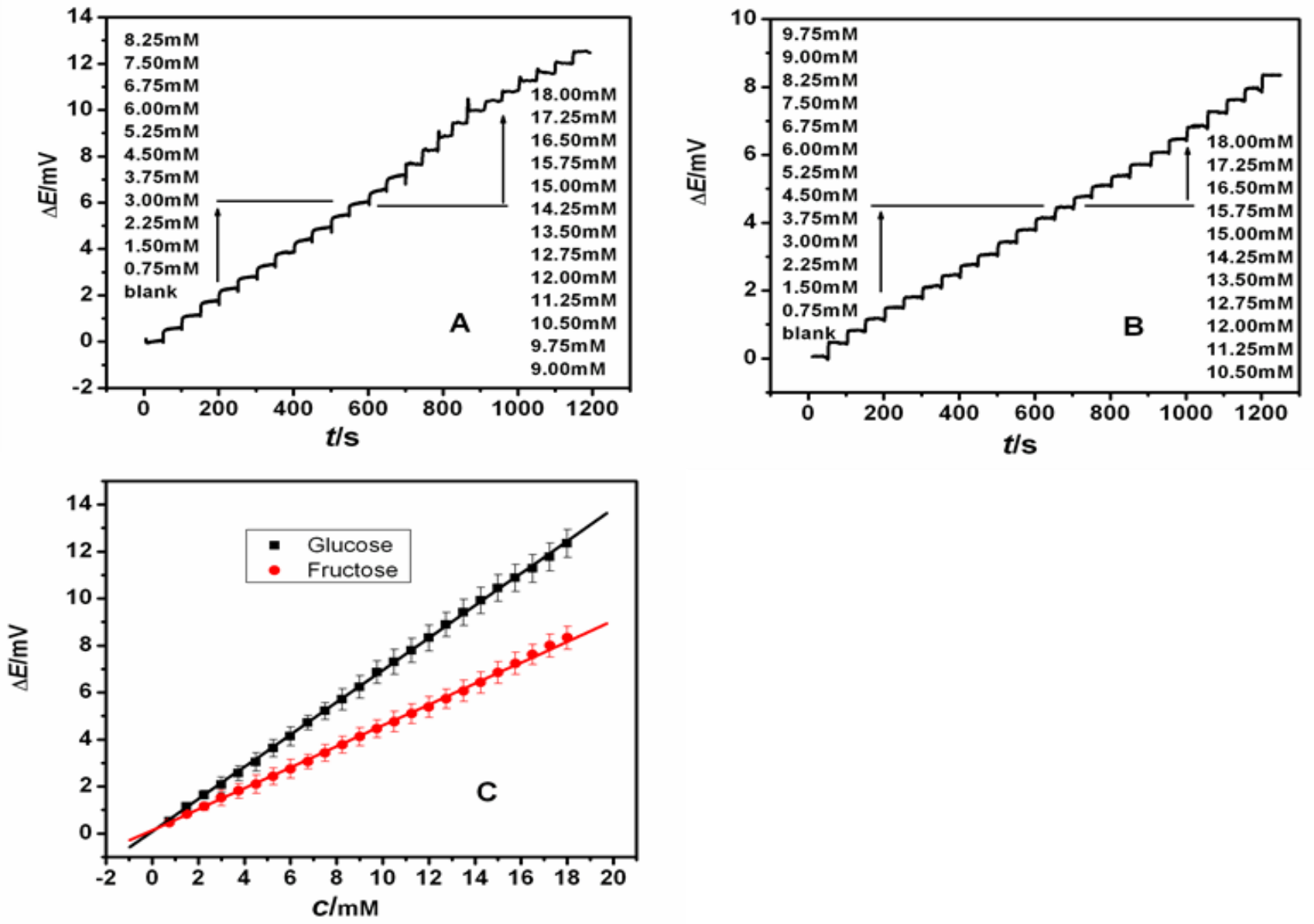

Figure. 5. (A) Potentiometric responses $(\Delta E)$ as a function of time at the Glu-MIP/GCE in $0.1 \mathrm{M}$ PBS (pH 10.0) containing different glucose concentration. (B) Potentiometric responses $(\Delta E)$ as a function of time at the FruMIP/GCE in $0.1 \mathrm{M}$ PBS (pH 10.0) containing different fructose concentration. (C) Calibration curve of $\Delta E$ vs. Concentration of glucose and fructose. 
Table 1. Comparison of detection range of reducing sugar sensors.

\begin{tabular}{|c|c|c|c|c|}
\hline Electrode matrix & $\begin{array}{l}\text { Reducing } \\
\text { sugars }\end{array}$ & $\begin{array}{c}\text { Linear } \\
\text { range } \\
(\mathrm{mM})\end{array}$ & $\begin{array}{l}\text { Detection } \\
\text { limit (mM) }\end{array}$ & Ref. \\
\hline $\begin{array}{l}\text { Poly (3-aminophenyl boronic } \\
\text { acid-co-3-octylthiophene) }\end{array}$ & D-Glucose & $0.5-50$ & 0.5 & [49] \\
\hline \multirow{2}{*}{ Poly(anilineboronic acid) nanotubes } & D-Glucose & $2.0-14.0$ & 0.5 & \multirow{2}{*}{ [29] } \\
\hline & D-Fructose & $2.0-14.0$ & 0.2 & \\
\hline ABBA/PSA/PSSA electrospun fibers-mat & D-Glucose & $0.75-14$ & 0.75 & [45] \\
\hline \multirow{2}{*}{ Polypyrrole-phenylboronic acid } & D-Glucose & $0.05-0.52$ & 0.008 & \multirow{2}{*}{ [24] } \\
\hline & D-Fructose & $0.25-1.25$ & 0.75 & \\
\hline \multirow{2}{*}{$\begin{array}{l}\text { Dithiobis(4-butyrylamino-m-phenylboronic } \\
\text { acid) }\end{array}$} & D-Glucose & $0.3-30$ & - & \multirow{2}{*}{ [27] } \\
\hline & D-Fructose & $3-300$ & - & \\
\hline \multirow{2}{*}{$\begin{array}{l}\text { P-Aminothiophenol SAM with } \\
\text { 4-formylphenylboronic acid }\end{array}$} & D-Glucose & $0.1-50$ & 0.0084 & \multirow{2}{*}{ [46] } \\
\hline & D-Fructose & $0.1-100$ & 0.035 & \\
\hline Chitosan/AuNPs composite & D-Glucose & $0.4-10.7$ & 0.37 & [47] \\
\hline $\begin{array}{c}\text { Poly(octylthiophene)-AuNPs } \\
\text {-(3-mercaptophenyl boronic acid) }\end{array}$ & D-Glucose & $5.0-30.0$ & 0.2 & [48] \\
\hline $\begin{array}{l}\text { GOx-based sensors with electrode } \\
\text { composited of MWCNTs-CS nanowire }\end{array}$ & D-Glucose & $1.0-10.0$ & N/A & [50] \\
\hline Graphene nanosheet & D-Glucose & $2-40$ & $3.0 \pm 0.5$ & [51] \\
\hline \multirow{2}{*}{$\begin{array}{l}\text { MIP(poly(3-hydroxyphenylboronic } \\
\text { acid-co-phenol)) }\end{array}$} & D-Glucose & $0.75-18$ & 0.23 & \multirow{2}{*}{$\begin{array}{l}\text { This } \\
\text { work }\end{array}$} \\
\hline & D-Fructose & $0.75-18$ & 0.35 & \\
\hline
\end{tabular}

\subsection{Selectivity}

To study the selectivity of Glu-MIP/GCE and Fru-MIP/GCE, some analogs such as sucrose, fructose, xylose and galactose were chosen as objective molecules to investigate the influence in the MIP sensor. As shown in Fig. 6, for the Glu-MIP/GCE (Fig. 6A) and Fru-MIP/GCE (Fig. $6 \mathrm{~B})$, a 5-fold excess of interferences hardly caused any significant change of potentiometric Am. J. Biomed. Sci. 2016, 8(1), 82-96; doi: 10.5099/aj160100082 responses $(\Delta E)$. The Glu-MIP/GCE has higher variation of potentiometric response occurred in presense of galactose (10.7\%) and fructose $(11.2 \%)$ than that of the other sugars (sucrose, xylose) which were less than $8.5 \%$ and had a slight increase upon the addition of these two interfering species. For Fru-MIP/GCE, the variation of potentiometric response also had a little change upon the addition of these interfering

(C) 2016 by NWPII. All rights reserved 
species. These results exhibited a good selectivity

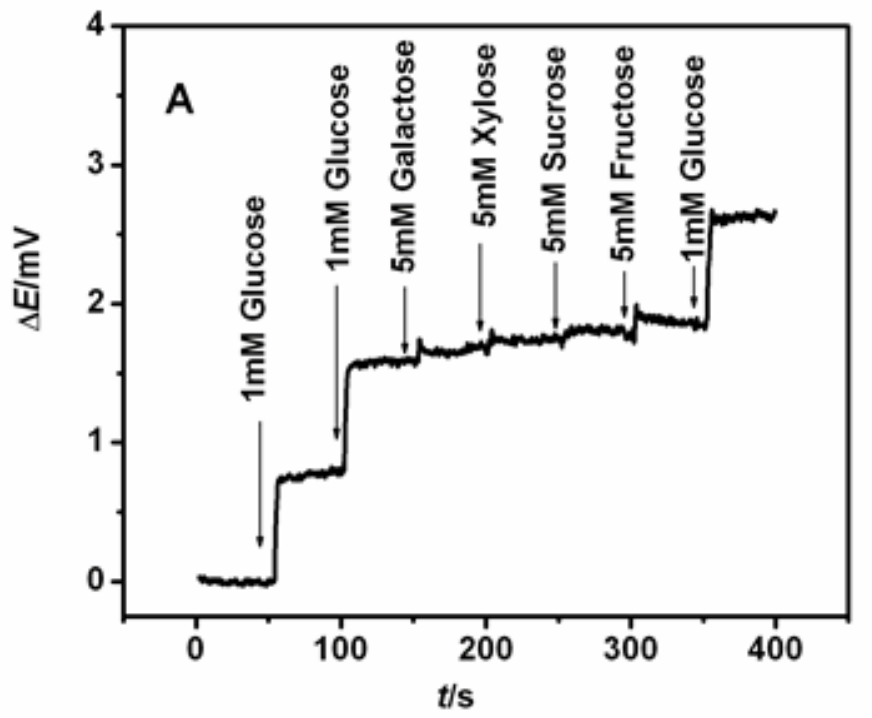

of MIP for glucose and fructose, respectively.

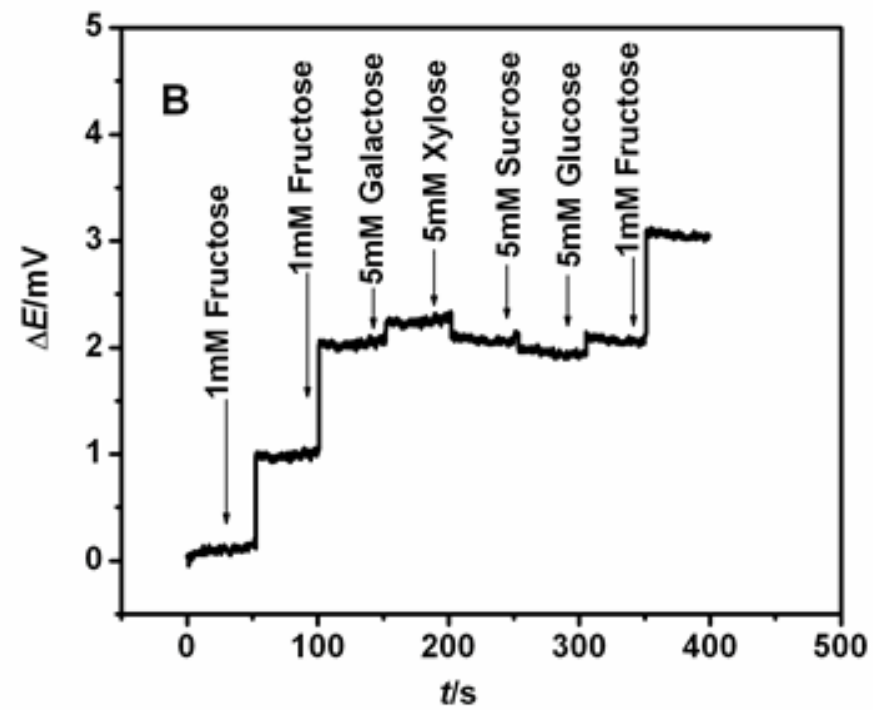

Figure. 6. (A) Potential change ( $\Delta E$ )-time curve at Glu-MIP/GCE after the successive addition. (a) $1 \mathrm{mM}$ glucose, (b) $1 \mathrm{mM}$ glucose, (c) $5 \mathrm{mM}$ galactose, (d) $5 \mathrm{mM}$ xylose, (e) $5 \mathrm{mM}$ sucrose, (f) $5 \mathrm{mM}$ fructose, (g) $5 \mathrm{mM}$ glucose. (B) Potential change $(\Delta E)$-time curve at Fru-MIP/GCE after the successive addition. (a) $1 \mathrm{mM}$ fructose, (b) $1 \mathrm{mM}$ fructose, (c) $5 \mathrm{mM}$ galactose, (d) $5 \mathrm{mM}$ xylose, (e) $5 \mathrm{mM}$ sucrose, (f) $5 \mathrm{mM}$ glucose, (g) $1 \mathrm{mM}$ fructose.

\subsection{Reproducibility and Stability}

The reproducibility of the sensor was tested by determining the potential change response of $1.0 \mathrm{mM}$ glucose in $0.1 \mathrm{M}$ PBS ( $\mathrm{pH} 10.0)$ with the same electrode three times and three different sensors prepared at room temperature under the same conditions. The same sensor determination result shows acceptable reproducibility with a relative standard deviation (RSD) of $1.8 \%$ for the potential change determined at a glucose concentration of $0.75 \mathrm{mM}$. The three electrodes showed an acceptable reproducibility in the potential change response to $0.75 \mathrm{mM}$ glucose with a RSD of $5.3 \%$, indicating good sensor-tosensor reproducibility. Moreover, the stability of the sensor is also an important factor to consider. To ensure the stability of the sensor, the response of the sensor after long-term storage was determined. The developed sensor was stored in 0.1 M PBS ( $\mathrm{pH} 10.0$ ) at room temperature and it retained a response of about $90 \%$ of the initial potential change response ever after one week.

\subsection{Real sample analysis}

The Glu-MIP/GCE and Fru-MIP/GCE was applied for the determination of glucose and Am. J. Biomed. Sci. 2016, 8(1), 82-96; doi: 10.5099/aj160100082 fructose in real sample. Watermelon juice and tomato juice obtained from sugar beet were used after dilution. A summary of the analytical results for each spiked sample is shown in Table 2 . Recoveries were calculated by comparing the potential change of the spiked sample with those of standard solutions following the same procedure. Owing to the high selectivity of MIP/GCE, good recoveries from 92.0-108.6\% were obtained. These results indicated that the sensor possess the capability in the determination of reducing sugars in sugar beet juice.

\section{Conclusion}

In the present study, the potentiometric detection of reducing sugars based on molecularly imprinted polymers modified on GCE was successfully developed. The imprinted polymer films for the selective analysis of glucose and fructose were prepared by the coelectropolymerization of the 3hydroxyphenylboronic acid and phenol-sugar complex. The results indicated that the MIP/GCE could be used for glucose or fructose determination in the present of galactose, xylose (c) 2016 by NWPII. All rights reserved 
and sucrose interferences and it was applied successfully in real sample determination.

Table 2. Determination of glucose and fructose in sugar beet juice samples $(n=3)$.

\begin{tabular}{|c|c|c|c|c|c|}
\hline & & Added (mM) & Found (mM) & Recovery (\%) & $\operatorname{RSD}(\%)$ \\
\hline \multirow{6}{*}{$\begin{array}{l}\text { Watermelon } \\
\text { Juice }\end{array}$} & \multirow{3}{*}{ Glucose } & - & 3.0 & - & 3.9 \\
\hline & & 3.0 & 6.0 & 100.0 & 2.3 \\
\hline & & 6.0 & 8.9 & 98.9 & 2.4 \\
\hline & \multirow{3}{*}{ Fructose } & - & 2.8 & - & 4.7 \\
\hline & & 3.0 & 6.3 & 108.6 & 3.9 \\
\hline & & 6.0 & 8.1 & 92.0 & 1.6 \\
\hline \multirow{6}{*}{$\begin{array}{l}\text { Tomato } \\
\text { juice }\end{array}$} & \multirow{3}{*}{ Glucose } & - & 7.2 & - & 3.6 \\
\hline & & 1.5 & 9.3 & 106.9 & 4.5 \\
\hline & & 3.0 & 10.7 & 105.0 & 2.1 \\
\hline & \multirow{3}{*}{ Fructose } & - & 2.0 & - & 4.5 \\
\hline & & 1.5 & 3.8 & 108.6 & 3.3 \\
\hline & & 3.0 & 5.2 & 104.0 & 4.2 \\
\hline
\end{tabular}

\section{Acknowledgements}

This work was financially supported by the National Natural Science Foundation of China (Nos. 21375033, 31501568), the Natural Science Fund for Creative Research Groups of Hubei Province of China (Nos. 2011CDA111, 2014CFA015), the Key Project of the Natural Science Foundation of Hubei Province (No. 2015CFA124) and the Program for Excellent Youth Scholars of Innovative Research Team of the Hubei Provincial Department of Education (T201101).

\section{References}

1. Joseph Wang, Electrochemical glucose biosensors, Chemical Reviews, 108(2008) 814-825. DOI: $10.1021 / \mathrm{cr068123a}$

2. Lakshmi N. Cella, Wilfred Chen, Nosang V. Myung and Ashok Mulchandani, Singlewalled carbon nanotube-based chemiresistive affinity biosensors for small molecules: Ultrasensitive glucose detection, Journal of the American Chemical Society, 132 (2010) 5024-5026. DOI: 10.1021/ja100503b

3. Daibing Luo, Liangzhuan $\mathrm{Wu}$ and Jinfang Zhi, Fabrication of boron-doped diamond nanorod forest electrodes and their application in nonenzymatic amperometric glucose biosensing, ACS Nano, 3 (2009) 2121-2128. DOI: $10.1021 / \mathrm{nn} 9003154$ 
4. Shabi Abbas Zaidi, Jae Ho Shin, Recent developments in nanostructure based electrochemical glucose sensors, Talanta, 149(2016)30-42.

DOI:10.1016/j.talanta.2015.11.033

5. C.M. Ma, Z. Sun, C.B. Chen, L.L. Zhang, S.H. Zhu, Simultaneous separation and determination of fructose, sorbitol, glucose and sucrose in fruits by HPLC-ELSD, Food Chemistry, 145 (2014) 784-788. DOI: 10.1016/j.foodchem.2013.08.135

6. F. Gao, F.B. Luo, X.X. Chen, W. Yao, J. Yin, Z. Yao, L. Wang, A novel nonenzymatic fluorescent sensor for glucose based on silica nanoparticles doped with europium coordination compound, Talanta, 80 (2009) 202-206. DOI: 10.1016/j.talanta.2009.06.050

7. X. Chen, J. Chen, F.B. Wang, X. Xiang, M. Luo, X.H. Ji, Z.K. He, Determination of glucose and uric acid with bienzyme colorimetry on microfluidic paper-based analysis devices, Biosensors and Bioelectronics, 35 (2012) 363-368. DOI: 10.1016/j.bios.2012.03.018

8. D. Harms, J. Meyer, L. Westerheide, B. Krebs, U. Karst, Determination of glucose in soft drinks using its enzymatic oxidation and the detection of formed hydrogen peroxide with a dinuclear iron (III) complex, Analytica Chimica Acta, 401 (1999) 83-90. DOI: 10.1016/S0003-2670(99)00514-0

9. P.N. Wahjudi, M.E. Patterson, S. Lim, J.K. Yee, C.S. Mao, W.P. Lee, Measurement of glucose and fructose in clinical samples using gas chromatography/mass spectrometry, Clinical Biochemistry, 43 (2010) 198-207. DOI: 10.1016/j.clinbiochem.2009.08.028

10. J.H. Wang, Y.Q. Li, H.L. Zhang, H.Q. Wang, S. Lin, J. Chen, Y.D. Zhao, Q.M. Luo, Bioconjugation of concanavalin and CdTe quantum dots and the detection of glucose, Colloids and Surfaces A: Physicochemical and Engineering Aspects, 364 (2010) 82-86. DOI: 10.1016/i.colsurfa.2010.04.041

11. Y.Q. Yang, C.L. Yi, J. Luo, R. Liu, J.K. Liu, J.Q. Jiang, X.Y. Liu, Glucose sensors based on electrodeposition of molecularly imprinted polymeric micelles: A novel strategy for MIP sensors, Biosensors and Bioelectronics, 26 (2011) 2607-2612.

DOI: $10.1016 /$ j.bios.2010.11.015

12. Weiwen $\mathrm{Hu}, \mathrm{Ge} \mathrm{Fu}$, Jinming Kong, Shufeng Zhou, Nikki Scafa, Xueji Zhang, Advancement of nucleic acid biosensors based on morpholino, American Journal of Biomedical Sciences, 7 (2015), 40-51. DOI: 10.5099/aj150100040

13. Xianwen Kan, Chen Li, Hong Zhou, Anhong Zhu, Zonglan Xing, Zhe Zhao and Guilin Xu, Three dimensional ordered macroporous electrochemical sensor for dopamine recognition and detection, American Journal of Biomedical Sciences, 4 (2012) 184-193. DOI: $10.5099 / a j 120300184$

14. B. L. C. Jr and C. Lyons, Electrode systems for continuous monitoring in cardiovascular surgery, Annals of the New York Academy of Sciences, 102 (1962) 29-45.

15. F. Li, Z. Wang, Y. Feng, Construction of bienzyme biosensors based on combination of the one-step electrodeposition and covalentcoupled sol-gel process, Science in China Series B: Chemistry Life Sciences \& Earth Sciences, 52 (2009) 2269-2274. DOI: 10.1007/s11426-009-0158-0

16. Subbiah Alwarappan, Chang Liu, Ashok Kumar and Chen-Zhong Li, Enzyme-doped graphene nanosheets for enhanced glucose biosensing, The Journal of Physical Chemistry C, $114(2010)$ 12920-12924. DOI: $10.1021 / \mathrm{jp} 103273 \mathrm{z}$

17. Olga Syshchyk, Valeriy A. Skryshevsky, Oleksandr O. Soldatkin, Alexey P. Soldatkin, Enzyme biosensor systems based on porous silicon photoluminescence for detection of glucose, urea and hevy metals, Biosensors and Bioelectronics, 66 (2015) 89-94. DOI: 10.1016/j.bios.2014.10.075

18. Nidhi Joshi, Kamla Rawat, Pratima R Solanki, H.B. Bohidar, Enzyme-free and biocompatible nanocomposite based cholesterol sensor, Biochemical Engineering Journal, 102 (2015) 69-73. DOI: 10.1016/j.bej.2015.01.006

19. Yuvaraj Haldorai, Jun Yeong Kim, A.T. Ezhil Vilian, Nam Su Heo, Yun Suk Huh, Young- 
Kyu Han, An enzyme-free electrochemical sensor based on reduced graphene oxide $/ \mathrm{Co}_{3} \mathrm{O}_{4}$ nanospindle composite for sensitive detection of nitrite, Sensors and Actuators B: Chemical, 227 (2016) 92-99. DOI: $10.1016 /$ j.snb.2015.12.032

20. $\mathrm{Na} \mathrm{Li,} \mathrm{Xia} \mathrm{Hao,} \mathrm{Bei} \mathrm{Hua} \mathrm{Kang,} \mathrm{Zhen} \mathrm{Xu,}$ Yan Shi, Nian Bing Li, Hong Qun Luo, Enzyme-free fluorescent biosensor for the detection of DNA based on core-shell $\mathrm{Fe}_{3} \mathrm{O}_{4}$ polydopamine nanoparticles and hybridization chain reaction amplification, Biosensors and Bioelectronics, 77 ( 2016) 525-529. DOI: 10.1016/j.bios.2015.10.004

21. S. Kabilan, J. Blyth, M.C. Lee, A.J. Marshall, A. Hussain, X.P. Yang, C.R. Lowe, Glucosesensitive holographic sensorsy, Journal of Molecular Recognition, 17 (2004) 162-166. DOI: 10.1002/jmr.663

22.C. Yu, V.W.W. Yam, Glucose sensing via polyanion formation and induced pyrene excimer emission, Chemical Communication, 11 (2009) 1347-1349.

DOI: 10.1039/B820397K

23. Y. Egawa, T. Seki, S. Takahashi, J. Anzai, Electrochemical and optical sugar sensors based on phenylboronic acid and its derivatives, Materials Science and Engineering C, 31 (2011) 1257-1264. DOI: 10.1016/j.msec.2011.05.007

24. S. Aytac, F. Kuralay, I.H. Boyac1, C. Unaleroglu, A novel polypyrrolephenylboronic acid based electrochemical saccharide sensor, Sensors and Actuators B, 160 (2011) 405-411. DOI: $\underline{10.1016 / \text { j.snb.2011.07.069 }}$

25. X. Wu, Z. Li, X.X. Chen, J.S. Fossey, T.D. James, Y.B. Jiang, Selective sensing of saccharides using simple boronic acids and their aggregates, Chemical Society Reviews, $42 \quad$ (2013) 8032-8048. DOI: $10.1039 /$ C3CS60148J

26. J. Li, L.L. Liu, P.G. Wang, J.B. Zheng, Potentiometric detection of saccharides based on highly ordered poly(aniline boronic acid) nanotubes, Electrochimica Acta, 121 (2014) 369-375.

DOI: $10.1016 /$ j.electacta.2013.12.162
27. S. Takahashi, J. Anzai, Phenylboronic acid monolayer-modified electrodes sensitive to sugars, Langmuir, 21 (2005) 5102-5107. DOI: $10.1021 / \mathrm{la050171n}$

28. E. Shoji, M.S. Freund, Potentiometric saccharide detection based on the $\mathrm{p} K_{\mathrm{a}}$ changes of poly(aniline boronic acid), Journal of American Chemical Society, 124 (2002) 12486-12493. DOI: $10.1021 / \mathrm{ja} 0267371$

29. J. Li, L.L. Liu, P.G. Wang, Y. Yang, J.B. Zheng, Amplified detection of saccharide based on redox-poly(phenol-co-3hydroxyphenylboronic acid) coupling with a redox cycling, Sensors and Actuators B, 198 (2014) 219-224. DOI: 10.1016/j.snb.2014.03.044

30. J. He, L.X. Song, S. Chen, Y.Y. Li, H.L. Wei, D.X. Zhao, K. Gu, S.S. Zhang, Novel restricted access materials combined to molecularly imprinted polymers for selective solid-phase extraction of organophosphorus pesticides from honey, Food Chemistry, 187 (2015) 331-337. DOI: 10.1016/j.foodchem.2015.04.069

31. L.F. Li, Y.Z. Liang, Y.C. Liu, Designing of molecularly imprinted polymer-based potentiometric sensor for the determination of heparin, Analytical Biochemistry, 434 (2013) 242-246. DOI: 10.1016/j.ab.2012.12.007

32. B.E. Granot, R. Tel-Vered, O. Lioubashevski, I. Willner, Stereoselective and Enantioselective, Electrochemical sensing of monosaccharides using imprinted boronic acid-functionalized polyphenol films, Advanced Functional Materials, 18 (2008) 478-484. DOI: 10.1002/adfm.200700498

33. L. Gu, X.Y. Jiang, Y. Liang, T.H. Zhou, G.Y. Shi, Double recognition of dopamine based on a boronic acid functionalized poly(anilineco-anthranilic acid)-molecularly imprinted polymer composite, Analyst, 138 (2013) 5461-5469. DOI: 10.1039/C3AN00845B

34. Y. Liu, L.H. Zhu, Z.H. Luo, H.Q. Tang, Fabrication of molecular imprinted polymer sensor for chlortetracycline based on controlled electrochemical reduction of graphene oxide, Sensors and Actuators B, 
185 (2013) 438-444.

DOI:

10.1016/j.snb.2013.05.044

35. M. Zarejousheghani, M. Möder, H. Borsdorf, A new strategy for synthesis of an in-tube molecularly imprinted polymer-solid phase microextraction device: Selective off-line extraction of 4-nitrophenol as an example of priority pollutants from environmental water samples, Analytica Chimica Acta, 798 (2013) 48-55. DOI: 10.1016/j.aca.2013.08.038

36. T. S. Anirudhan, S. Alexander, Design and fabrication of molecularly imprinted polymer-based potentiometric sensor from the surface modified multiwalled carbon nanotube for the determination of lindane $(\gamma$ hexachlorocyclohexane), an organochlorine pesticide original research article, Biosensors and Bioelectronics, 64 (2015) 586-593. DOI: 10.1016/j.bios.2014.09.074

37. Z.H. Wang, F. Li, J.F. Xia, L. Xia, F.F. Zhang, S. Bi, G.Y. Shi, Y.Z. Xia, J.Q. Liu, Y.H. Li, L.H. Xia, An ionic liquid-modified graphene based molecular imprinting electrochemical sensor for sensitive detection of bovine hemoglobin, Biosensors and Bioelectronics, $61 \quad$ (2014) 391-396. DOI: 10.1016/j.bios.2014.05.043

38. L. Qin, X.W. He, W. Zhang, W.Y. Li, Y.K. Zhang, Surface-modified polystyrene beads as photografting imprinted polymer matrix for chromatographic separation of proteins, Journal of Chromatography A, 1216 (2009) 807-814. DOI: 10.1016/j.chroma.2008.12.007

39. D. Jégourel, R. Delépée, F. Breton, A. Rolland, R. Vidal, L.A. Agrofoglio, Molecularly imprinted polymer of 5methyluridine for solid-phase extraction of pyrimidine nucleoside cancer markers in urine, Bioorganic \& Medicinal Chemistry, 16 (2008) 8932-8939. DOI: 10.1016/j.bmc.2008.08.063

40. J.F. Yin, G.L. Yang, Y. Chen, Rapid and efficient chiral separation of nateglinide and its L-enantiomer on monolithic molecularly imprinted polymers, Journal of Chromatography A, 1090 (2005) 68-75. DOI: $\underline{10.1016 / j . c h r o m a .2005 .06 .078}$
41. R. Thoelen, R. Vansweevelt, J. Duchateau, F. Horemans, J. D'Haen, L. Lutsen, D. Vanderzande, M. Ameloot, M. vandeVen, T.J. Cleij, P. Wagner, A MIP-based impedimetric sensor for the detection of lowMW molecules, Biosensors and Bioelectronics, 23 (2008) 913-918. DOI: 10.1016/j.bios.2007.08.020

42. Z.P. Yang, C.J. Zhang, Designing of MIPbased QCM sensor for the determination of $\mathrm{Cu}$ (II) ions in solution, Sensors and Actuators B, 142 (2009) 210-215. DOI: 10.1016/j.snb.2009.08.029

43. Y. Yang, C.L. Yi, J. Luo, R. Liu, J.K. Liu, J.Q. Jiang, X.Y. Liu, Glucose sensors based on electrodeposition of molecularly imprinted polymeric micelles: a novel strategy for MIP sensors, Biosensors and Bioelectronics, 26 (2011) 2607-2612. DOI: 10.1016/j.snb.2009.08.029

44. E. Shoji, M.S. Freund, Potentiometric sensors based on the inductive effect on the $\mathrm{p} K_{\mathrm{a}}$ of poly(aniline): A nonenzymatic glucose sensor, Journal of American Chemical Society, $123 \quad$ (2001) 3383-3384. DOI: $10.1021 / \mathrm{ja005906j}$

45. A. Tiwari, D. Terada, C. Yoshikawa, H. Kobayashi, An enzyme-free highly glucosespecific assay using self-assembled aminobenzene boronic acid upon polyelectrolytes electrospun nanofibers-mat, Talanta, 82 (2010) 1725-1732. DOI: 10.1016/j.talanta.2010.07.078

46. Y.Q. Zhao, H.Q. Luo, N.B. Li, A sensitive non-enzyme sensing platform for glucose based on boronic acid-diol binding, Sensors and Actuators B, 161 (2012) 832-837. DOI: 10.1016/i.snb.2011.11.042

47. D. Feng, F. Wang, Z.L. Chen, Electrochemical glucose sensor based on onestep construction of gold nanoparticlechitosan composite film, Sensors and Actuators B: Chemical, 138 (2009) 539-544. DOI: 10.1016/j.snb.2009.02.048

48. H. Ciftci, U. Tamer, Functional gold nanorod particles on conducting polymer poly(3octylthiophene) as non-enzymatic glucose sensor, Reactive and Functional Polymers, 72 
(2012)

127-132.

DOI:

10.1016/j.reactfunctpolym.2011.11.006

49. H. Ciftci, U. Tamer, M.S. Teker, N. Pekmezc, An enzyme free potentiometric detection of glucose based on a conducting polymer poly (3-aminophenyl boronic acid-co-3octylthiophene), Electrochimica Acta, 90 (2013) 358-365.

DOI: 10.1016/j.electacta.2012.12.019

50. P. Gomathi, K. Min, P. Kwan, D. Je Jung, A. Ragupathy,L. Rajendran, S. Chool, K. Jae Chang, L. S. Hak and G. Han, Do Multiwalled carbon nanotubes grafted chitosan nanobiocomposite: A prosperous functional nanomaterials for glucose biosensor application, Sensors and Actuators B: Chemical, 155 (2011) 897-902. DOI: 10.1016/j.snb.2010.12.050

51. S. Alwarappan, C. Liu, A. Kumar and C.Z.Li, Enzyme doped graphene nanosheets for enhanced glucose biosensing, The Journal of Physical Chemistry C, 114 (2010) 1292012924. DOI: 10.1021/jp103273z

52. Chao Chen, Qingji Xie, Dawei Yang, Hualing Xiao, Yingchun $\mathrm{Fu}$, Yueming Tan and Shouzhuo Yao, Recent advances in electrochemical glucose biosensors: a review, RSC Advances, 3 (2013) 4473-4491. DOI: $10.1039 / \mathrm{C} 2 \mathrm{RA} 22351 \mathrm{~A}$ 